\title{
Road Accident Mapping along Halsema Highway
}

\author{
Dr. Claire Kaplaan P. Lafadchan \\ Mountain Province State Polytechnic College, \\ Bontoc, Mountain Province, Philippines
}

\begin{abstract}
This paper showcases the profile of the road accident rate that happened along the Halsema Highway and the determination of road accident hotspots through QGIS mapping. This research used the qualitative research design and descriptive method using documentary analysis to determine the road accident rate profiles. On-site observation was conducted to describe the physical set-up of the accident prone areas; while interviews with police officers, commuters and drivers were conducted to supplement the findings of the study. It was found that most road accidents happen during the $2^{\text {nd }}$ quarter of the year. More accidents happen during weekends between 12:00 at noon and 4:00 in the afternoon. It was also revealed that vehicle-to-vehicle is the most common type of collision. Looking at the accident map, Usok Area, Amlosong, Balili, SitioPalinga-aw, Namatec, Mount Data Cliff and Mount Data Sawmill are identified as accident prone areas. The findings indicate that road accidents choose no place, weather or person. It happens at any time regardless of vehicle type.
\end{abstract}

Keywords: accident mapping, Halsema highway, mountain province, QGIS, road accident.

\section{Introduction}

Human beings have gone far on the waves of changing times, and transportation is a major element of the modern world. Vehicles have upgraded to luxury cars and contemporary means of conveyance that must meet the standards set by newly crafted laws and policies. Road settings are somehow engineered to ensure safety; while research continues to discover specifications that would help reduce road and traffic accident since motor vehicle is becoming a necessity to people.

Yet, according to the World Health Organization Report (2015), road traffic accidents is a growing issue which cause social and economic lose and an average of 1.25 million deaths per year. Despite the technology and design the governments adopt, road safety is still a main concern in many countries. In Europe, according to Brijs and Moons (2009), road safety is a high priority in research since road accidents are higher compared with other types of transportation.

In Maryland, the Crime Mapping and Analysis Program (CMAP) developed by the Washington College collects traffic accident data for mapping and analysis used by the Maryland State Police (MSP). This detailed mapping and analysis are performed by collecting all traffic accident data for the entire state of Maryland and dividing this data into the 22 Maryland State Police Barrack Districts (Washington College GIS, 2014).

Shafabakhsh, Famili and Bahadori (2017) also conducted a research on traffic accident rate to understand traffic accident patterns in Masshad City in Iran using the Geographic Information System and were able to present classifications in defining the eventfulness of the study area. In relation to collision type, Herrman and Herrman (2016) posted an article which identified the top five most common types of auto accidents which are enumerated as vehicle rollover, single car accident, rear-end collision, side-impact collision and head-on collision. In addition, Bigham (2014) speculated that traffic collision occurs when a vehicle treats with another vehicle, pedestrian, animal 
or geographical or structural barriers which could lead to physical or financial harm and death. In the Philippines, road accident is the fourth leading cause of death with 36,000 cases yearly. This number includes all forms of road accidents. Punay (2017) also mentioned in his article that 34 Filipinos are killed daily in road accidents.

With the growing number of vehicular accidents in the Philippines, the Traffic Accident Recording Analysis System (TARAS) was developed by the Department of Public Works and Highways (DPWH) to collect road crash data from the Philippine National Police (PNP). TARAS was intended to identify road safety black spots and implement the necessary countermeasures, but it was discontinued in 2013 due to logistical challenges of training and re-training PNP officers, as well as supplying traffic accident record forms to the 1,500 police stations nationwide (Sy, 2017). After TARAS, the Philippine Statistics Authority (PSA) consolidated nationwide data on road crashes.

"Cordillera Administrative Region (CAR) roads are highly susceptible to road cuts/closures and accidents. The roads in CAR incurred the highest in the annual number of road closures at 981 from 2004-2005, affecting some 238 kilometers of national roads and resulting in roughly Php1.171 billion in losses. Moreover, CAR roads are accident prone with the region placing 6th nationwide in 2007 in road accident frequency at 312, with eight incidents or 3 percent traced to road defects," (CARDP, 2010).

Between 2010 and 2011, the Department of Health reported that Cordillera Administrative Region had 105 road accident-related deaths with 360 people injured; 26 road accident-related deaths in 2012; 74 in 2013; while over 120 deaths were recorded in 2014 and over 1,000 injuries in Cordillera (Palangchao, 2014).

One major road that connects provinces in the Cordillera is the Halsema Highway, a road system that forgives no mistake among road users. It runs directly towards Bontoc which is located at the heart of the mountain ranges of Mountain Province and one can reach the place through the foggy, narrow zigzag roads, with steep slopes and deep gorges which means death if travelers commit a single mistake. Yet, Bontoc is becoming a tourist destination since it offers a variety of natural wonders and cultural festivals for both local and foreign tourists. It is also becoming a side trip target to some tourists who come from the tourist spots in Sagada and other nearby municipalities.

There are many studies on the analysis of traffic and road accidents using different methods such as algorithm, data mining and simulations but most of those researches were studies in urban areas where the topography is flat. Terrain makes this research unique since Halsema Highway stretches along the mountain ranges and passes through rural areas.

Due to the inevitability of road accidents, it is significant to identify the road accident hotspots and understand how safety should be implemented in all road systems. This research followed the idea of Deka and Quddus (2013) that accident records need to be validated, and accidents should be mapped on the correct links before being analyzed to improve safety applications. They added that the underlying concept of most of the accident mapping endeavors has been towards integration of the database of police accident reports with the road network database. Hence, Kumar and Toshniwal (2016) also posited in their research that the identification of road accident helps in the identification of the factors that contribute to accident frequencies at the area.

Consequently, this study is concentrated on the determination of the road accident profile of the Halsema Highway from Chakchakan, Bontoc to Sinto, Bauko according to road accident rate and type of collision; and to map the road accidents to identify the hotspots. The research is necessarily conducted to benefit the public utility vehicle drivers who pass along the Mountain Province Highway every day in order to make a living and all other road users. Thus, determinant variable theory is regarded in this study since determination of factors common in accidents can be possible if data is collected correctly (Benner, 1979). The concepts of the 5 Es of Traffic Management are also essentially considered in this research since Education, Enforcement, Engineering, Environment, Economics and Evaluation need to be reflected in road safety. 
The study was conducted in Mountain Province, most specifically the Mountain Province Section of the Halsema Highway which stretches from Sinto, Bauko to Chakchakan, Bontoc. This specified section is also referred in the study as the Halsema Highway. Chakchakan to Central Bontoc road was not included in the scope of the study since this section of the highway is congested and it is believed that there are other factors that cause road accidents along it.The study only focused on the records consolidated by the Mountain Province Police Provincial Office from calendar year 2013 to 2016.

\section{Methods}

\section{Participants}

Four police officers who usually respond to road accident reports, five drivers and ten commuters were interviewed to validate the identified accident hotspots along the Mountain Province Section of the Halsema Highway which stretches from Sinto, Bauko to Chakchakan, Bontoc.

\section{Design}

Qualitative design since documentary analysis was employed in determining the road accident profile while data analysis was used to determine the accident prone areas through QGIS mapping. Frequency counting was used to determine the road accident profile and type of collision. The gathered data on road accident rate and type of collision were mapped using Quantum Geographical Information System (QGIS) software to determine the road accident prone areas. The QGIS is open and free-download software that allows users to input data for geo-mapping and allows the users to view and analyze spatial data. In addition, as mentioned by Htut, et al. (2016), the Geographic Information System (GIS) assists users to recognize dangerous locations and acquire the accident location's ranking quickly.

\section{Materials}

Document analysis was used to define the profile of road accidents along the specified stretch of Halsema Highway. The documents analyzed are reported vehicular accidents consolidated by the Mountain Province Police Provincial Office (MPPPO) which were duly retrieved by the researcher. The data were filtered according to profile and specific locale of the study. The data gathered from the Mountain Province Police Provincial Office are road accident rate according to month and time of the day; types of collision; weather condition and road features. Frequency counting was used to answer specific problems. An on-site survey and observation was conducted by the researcher to properly describe the physical make-up of the identified accident prone areas which contributes to the occurrence of road accidents. Interview was conducted to augment the findings of the study.

\section{Procedure}

The researcher sent a request letter to the provincial director of Mountain Province Police Provincial Office for the data needed to determine the profile of the road accident rate along the Mountain Province Highway. Data gathering proceeded. The interpretation of data was done following the frequency counting to determine the profile of road accident rate. After identifying the accident hotspots, the researcher conducted an on-site survey. The researcher then proceeded to the determination of the results and implications of the study.

\section{Results}

The profile of the road accidents along the Mountain Province Highway from year 2013-2016 reflects that most accidents happened in 2015.

Table 1: Profile of accident rate per year

\begin{tabular}{|l|l|l|}
\hline Year & Frequency & Difference \\
\hline 2013 & 41 & \\
\hline 2014 & 42 & $2.44 \%$ \\
\hline 2015 & 54 & $22.22 \%$ \\
\hline 2016 & 48 & $-11.11 \%$ \\
\hline Total & $\mathbf{1 8 5}$ & \\
\hline
\end{tabular}


April and July are the months with the most accident occurrences from year 2013 to 2016. These months are the times when rain pours which can affect road conditions leading to road accidents.

Table 2: Accident rate according to quarter and months

\begin{tabular}{|c|c|c|c|c|c|}
\hline $\begin{array}{l}\text { Quarterly } \\
\text { Rate }\end{array}$ & Frequency & Percentage & Month & Frequency & Percentage \\
\hline \multirow{3}{*}{$\begin{array}{l}1^{\text {st }} \\
\text { Quarter }\end{array}$} & \multirow[t]{3}{*}{35} & \multirow[t]{3}{*}{$18.9 \%$} & January & 15 & $8.1 \%$ \\
\hline & & & February & 10 & $5.4 \%$ \\
\hline & & & March & 10 & $5.4 \%$ \\
\hline \multirow{3}{*}{$\begin{array}{l}2^{\text {nd }} \\
\text { Quarter }\end{array}$} & \multirow[t]{3}{*}{58} & \multirow[t]{3}{*}{$31.35 \%$} & April & 30 & $16.2 \%$ \\
\hline & & & May & 17 & $9.1 \%$ \\
\hline & & & June & 11 & $5.9 \%$ \\
\hline \multirow{3}{*}{$\begin{array}{l}3^{\text {rd }} \\
\text { Quarter }\end{array}$} & \multirow[t]{3}{*}{51} & \multirow[t]{3}{*}{$27.5 \%$} & July & 20 & $10.8 \%$ \\
\hline & & & August & 13 & $7 \%$ \\
\hline & & & September & 18 & $9.7 \%$ \\
\hline \multirow{3}{*}{$\begin{array}{l}4^{\text {th }} \\
\text { Quarter }\end{array}$} & \multirow[t]{3}{*}{41} & \multirow[t]{3}{*}{$22.16 \%$} & October & 12 & $6.4 \%$ \\
\hline & & & November & 13 & $7 \%$ \\
\hline & & & December & 16 & $8.6 \%$ \\
\hline Total & \multicolumn{2}{|l|}{185} & Total & \multicolumn{2}{|l|}{185} \\
\hline
\end{tabular}

The result also shows that the most accidents happen during the day from 8:00 in the morning to 8:00 in the evening than during night time.

Table 3: Accident rate according to time

\begin{tabular}{|l|l|l|}
\hline Time of the day & Frequency & Percentage \\
\hline $24: 00-4: 00$ & 13 & $7 \%$ \\
\hline $4: 00-8: 00$ & 18 & $10 \%$ \\
\hline $8: 00-12: 00$ & 50 & $27 \%$ \\
\hline $12: 00-16: 00$ & 52 & $28 \%$ \\
\hline 16:00-20:00 & 38 & $20.5 \%$ \\
\hline $20: 00-24: 00$ & 14 & $7.5 \%$ \\
\hline Total & $\mathbf{1 8 5}$ & \\
\hline
\end{tabular}

It was found out that vehicle-to-vehicle is the most common type of collision that happened wherein two vehicles coming from opposing lanes collide.

Table 4: Type of collision

\begin{tabular}{|l|l|l|}
\hline Type of collision & Frequency & Percentage \\
\hline Vehicle to vehicle to & 89 & $48 \%$ \\
\hline $\begin{array}{l}\text { Vehicle } \\
\text { human/object }\end{array}$ & 62 & $33 \%$ \\
\hline Lone accident/plunging & 31 & $17 \%$ \\
\hline Others & 3 & $2 \%$ \\
\hline Total & $\mathbf{1 8 5}$ & \\
\hline
\end{tabular}

There are three identified accident hotspots in the Municipality of Bontoc. These are the Usok Area, Amlosong and Balili; while two are identified at the Municipality of Sabangan which are located at SitioPalinga-aw at Barangay Lagan and the national road at Barangay Namatec. Mount Data Cliff and Mount Data Sawmill were identified as road accident hotspots along the national road that passes through the Municipality of Bauko. 


\section{Discussion}

\section{Profile of Road Accidents along the specified stretch of the Halsema Highway}

Road accident rate along the Mountain Province section of the Halsema Highway, for the past four years, reflects the dangers brought about by various factors that contribute to accidents that are fatal and less serious. There is $2.44 \%$ increase on road accident rate from 2013 to 2014 and another $22.22 \%$ increase in 2015 . However, a decrease of $11.11 \%$ on the road accident rate was noted in 2016 when almost the whole stretch of the Mountain Province Highway is well paved and cemented.

It is reflected in Table 2 that most accidents occur on the months of April with a frequency of 30 while July, September and May are closely following each other along with the rest of the months. The top three road accident rates per month are almost close which may support the notion that accident choose no time for it to happen. Looking closely at the month with the highest incidences of road accident, April is a vacation month, and it is also the time of the year in Mountain Province when rain starts to fall. The weather affects the road condition since stones and rocks from the mountain slope fall to the road when it rains making the road slippery and unsafe. The hot temperature during the days also affects driving condition and behavior of the driver.

It can be gleaned on Table 3 that road accidents mostly happen during the day between 8:00 to 4:00 in the afternoon. Looking at the hourly grouping, there are 52 road accident occurrences that happened from 12:00 at noon and 24:00 in the evening and 50 incidents occurred from 8:00 in the morning to 12:00 at noon. Both of the groupings fall during the day. This finding is supported by the report of the Royal Society for the Prevention of Accidents (ROSPA, 2017) that between 2pm and $4 \mathrm{pm}$ (especially after eating or having even one alcoholic drink). The team of researchers of JP Research (2015) also found out that most fatal accidents in Ahmedabad and Gandhinagar districts in India occur between 12:00 to 17:59.

The second highest is 50 occurrences which happened between 8:00 in the morning and 12:00 at noon. It can be rationalized that most people like to travel in the morning to avoid fogs and to have more time to rest upon reaching their destination so most of the time, the Halsema Highway becomes busy in the morning. In an interview with SPO2 Falolo, he stated that among the negative discernment of drivers is the false notion that they can still manage to drive home or reach their destination despite the lack of sleep or little effect of alcohol to their system. In connection to this, most accidents that happened between 8:00 in the morning and 12:00 at noon involved drivers who experienced fatigue and sleepiness since they started travelling at wee hours and were on the road too long.

The third highest road accident frequency is 202 that happened between 4:00 in the afternoon and 8:00 in the evening. This result is consistent with the research of Bhagyaiah and Shrinagesh (2014 cited that most accidents happen between 4:00 in the afternoon and 8:00 in the evening as reflected on the hourly accident cases in Hyberadad. In the study of Alam and Ahsan (2013), their findings show that most accidents occur during day time with $80 \%-85 \%$ as compared to accidents that happen during night time and at dawn with $16 \%$ and $20 \%$ respectively. Sharma (2016) also mentioned that more than $70 \%$ of accidents occur between $7 \mathrm{AM}$ and $7 \mathrm{PM}$.

Table 3 also reflects that there were only 37 road accidents that happened between 12:00 midnight and 4:00 in the morning. This can be explained by the fact that there are a few people who travel during these times. Elliot (2009) cited that fewest crash in 2007 from 4:00 a.m. and 5:00 a.m. when traffic is lesser.

The close gap on the number of road accident occurrences along Halsema Highway in terms of month, days of the week and hours, imply that accidents really happen any time. It is also given that the temperature of the mid-day is hot which would have affected the condition and behavior of drivers while weather has also an impact on the road condition which is considered as a factor in the occurrence of accidents.

It is reflected on Table 4 that vehicle to vehicle collision has the highest frequency of 89 . Vehicle to vehicle collision occurs when two or more vehicles collide with each other. It includes 
heads-on collision, rear-end collision, bumped vehicle, bumped rear-end or side-impact collision. This type of collision usually happens in curves where drivers cannot immediately see if there is an approaching vehicle. It also happens when one vehicle encroach the other lane due to sleepiness/fatigue or distraction.

The type of collision with the second highest frequency is vehicle to human or object with 62. Vehicles hit objects or human because the driver is either sleepy or inattentive. Sometimes, drivers hit objects or mountain slope rather than to hit pedestrians who suddenly appear to cross the road. Sometimes, drivers slam into the barriers when the road is slippery. As cited by Elias and Bahaudin (2014), deaths from road accidents occur due to collision between vehicles, pedestrians or any roadside signage and billboards.

Collision between vehicle and human is quite lesser since this type of collision happens only in sections of the highway that are congested and in sections of the road where parked vehicles block the line of view of drives, thereby not noticing crossing pedestrians. Site visit revealed that accidents involving pedestrians happen near school zones where children cross the road to reach school.

The third type of collision is lone accident or vehicle plunging with a frequency of 31 . Lone accidents refer to cases when vehicles or motorcycles run off the lane and fell. It also includes accidents that happened due to tripping on the side or when a vehicle is hit by falling rocks. It was also found out that driver condition is a factor in lone accidents, especially when the driver is under the influence of liquor. According to PO2 Lobchoy, "most lone accidents involve motorcycles because of over speeding."

The last is others with a frequency of 2. According to Mr. Elijah Bagni, the crime statistician at Mountain Province Police Provincial Office, "Others refer to unreported type of collisions due to immediately settled vehicular accident cases and lone accidents where nobody files a case." Thus, vehicle to vehicle collision, either head-on, bumped rear side or side-swept, result to fatal accidents such as death and serious physical injuries where a driver was either driving under the influence of liquor, sleepy or driving too fast.

\section{Road Accident Mapping from Chakchakan, Bontoc to Sinto, Bauko}

To determine the road accident "hotspot", yearly occurrences of accidents in one area is considered. The hotspots were identified by looking at the road accident map tagged using the QGIS. The locations were then confirmed by the responding officers and drivers who were interviewed.

\section{Usok Area}

This accident prone area is confirmed to be an accident hotspot by the interviewed police officers and drivers. The consolidated record of road accidents at MPPPO showed that there are ten (10) accidents that happened near and around this spot. The Usok area refers to the tunnel and the sharp curve road around the tunnel. The Usok area can be considered as an accident "hotspot".

Site visitation reveals that the Usok area is a potential accident zone since it is located in a sharp curve and a tunnel. Usually, smaller vehicles pass through the tunnel while bigger trucks and buses take the outer sharp curve. Accidents happen in this place because of lack of perception of hazard on the part of the drivers when they yield or slowdown to wait for incoming vehicles. Most accidents that happened at the Usok area are vehicle-to-vehicle collisions wherein drivers are supposed to be attentive on the road and to be cautious in driving; but then, accidents occur since the drivers are not careful and vigilant on the sharp curve that they cannot see the approaching vehicle on the opposite direction.

The physical set-up of the Usok area is a potential danger itself; thus, it requires alertness and vigilance when traversing along it. Driver behavior is a factor in the occurrence of road accidents along this section of the highway since the drivers are less careful when driving. Accidents could be avoided in this area if the drivers give-in to road signs, pavement marking, and if they portray courtesy to consider other road users. 


\section{Amlosong Area}

Another identified "hotspot" is at Amlosong Area which is quite a straight and fairly wide path. From the database at the MPPPO, there are six (6) accidents that happened along this area. The causes of accidents here are driving too fast and inattentiveness. According to one passenger, some drivers rev-up when they approach this site and some of them chase each other in overtaking. Negligence on the part of the drivers is one of the factors that contribute to road accident along Amlosong.

\section{Sitio Malitep}

The third accident "hotspot" is at SitioMalitep, Balili which is a zigzag road. Five (5) accidents happened here from 2013-2016. Driving too fast and inattentiveness are the causes of road accidents along this stretch of the highway. The accidents that happened along this section are falling/plunging vehicle, hit object, head-on collision and side-swept. Heads-on collision happens here because of its straight-flat feature which gives a chance for motorists to encroach lanes or overspeed.

\section{Sitio Palinga-aw}

At the Sabangan section, seven (7) accidents occurred at SitioPalinga-aw at Barangay Lagan which is also considered as an accident hotspot. The types of collision that usually happen in this area are lone accident/plunging like hit object and overturned; and vehicle-to-vehicle collision such as hit parked vehicle and head-on collision. Road accidents usually happen at the curve at Palinga-aw. During the site visit conducted by the researcher, it was noted that the road at Palinga-aw is a twoway lane, but vehicles are parked alongside its stretch going to the Nacagang bridge. This may have influenced the hit-object collisions and the hit parked vehicle since the road becomes narrow due to illegally parked vehicles.

\section{Sitio Tala}

SitioTala, Namatec section is also determined as a road accident hotspot since head-on collision, hit object, and hit pedestrian usually happen there. There were five (5) road accidents happened in this area. It is observed that during rainy season, fog covers the higher parts of Sabangan like Pingad and Namatec especially on the early morning and late afternoon. The road is also zigzagging as it ascends towards Mount Data. Slippery when wet are road signs installed along Namatec which may indicate that drivers need to shift to low gear when traversing the area.

\section{Mount Data Cliff}

This area is identified as a road accident hotspot along the Halsema Highway because of its road condition. It is prone to partial road washout, falling rock from the cliff, and slippery when wet due to rain and shower. The physical characteristics is also straight-flat and monotonous. These features can also affect the driver's behavior, especially when the driver is drowsy or experiencing fatigue. Hit object and vehicle-to-vehicle collision are the common types of accidents that happen along this stretch. As posited by Ahmed, Ahmed and Hainin (2014), traffic accidents are dominant in straight and flat roads $(97 \%)$ of Dhaka City. This supports the finding of the study that a road feature which is straight-flat can be a possible accident hotspot.

\section{Mount Data Sawmill}

"Slippery When Wet" is also the signage that warns the drivers along Mount Data Sawmill, Upper Bauko since the tires of the vehicle slip when it rains, and the soil falls down to the road, affecting the rotation of the tires. There were six (six) recorded accidents along this stretch. Hit pedestrian and hit objects are the common accidents that happen along this part of the Halsema Highway. This section has a road feature of the inclined curve where some vehicles skid when it is raining due to pebbles, sand, and wet surface.

Looking at the identified accident hotspots, there are road signs posted alongside it such as "falling rocks" and "slippery when wet" which indicate that the road condition is also affected by its surrounding and the roads become treacherous with the intervention of weather, especially rain.

The identified accident hotspots are along straight-flat road and around curve areas of the highway which mean that road feature is not merely the cause of road accidents. Weather condition and driver behavior need to be considered in road accidents. 
From the data analysis, the profile of road accidents along the Mountain Province Highway that happened from Chakchakan, Bontoc to Sinto, Baukobetwee years 2013-2016 highlights April and July as the months having high rates of road accidents which usually happen during day time from 8:00 in the morning to 4:00 in the afternoon. The most common type of collision that happened is vehicle to vehicle. Seven road accident hotspots were identified along the Mountain Province Highway through road accident mapping and these are Usok area, Amlosong, Balili, SitioPalinga-aw at Lagan, Namatec, Mount Data Cliff and Mount Data Sawmill. These accident hotspots were verified by the police officers who respond to road accident reports and the drivers who usually traverse the Halsema Highway.

\section{Conclusion}

The following conclusions were drawn from the results and findings of the study:

1. Accidents happen at any time regardless of vehicle type, so safety need to be always considered as a priority in travelling.

2. The identified accident hotspots have different features. Some are straight-flat while some are located along curve section of the highway.

\section{References}

Alam, M., \& Ahsan, H. (2013). Identification and Characterization of Hazardous Road Locations on DhakaChittagong National Highway. Global Journal of Research in Engineering, General Engineering, 13 (4).

Bhagyaiah, M. \& Shrinagesh, B. (2014). Traffic analysis and road accidents: A case study of Hyberabad using GIS. Paper presented at IOP Conference Series: Earth and Environmental Science, 20(1), 1-9.

Bigham, B. (2014). Road accident data analysis: A datamining approach. Indian Journal of Scientific Research, 3(3), 437-443.

National Economic and Development Authority. (2010). Cordillera Regional Development Plan 2011-2010. Retrieved from http://www.neda.gov.ph/wp-content/uploads/2013/10/CAR_RDP_20112016.pdf.

Elias, E., Bahaudin, A., \& Mahidin, M. (2014). An empirical study of road accidents: influence of the costing of living. Paper presented at An International Conference of Technology Management, Kuala Lumpur: PWTC.

Elliot, H. (2009). Most dangerous times to drive. Forbes. Retrieved from https://www.forbes.com/2009/01/21/car-accident-times-forbeslifecx_he_0121driving_slide.html\#58f356ff1e80.

Herrman \& Herrman. (2016). Types of Vehicle Accidents. Retrieved from https://www.herrmanandherrman.com/blog/types-vehicle-accidents/.

Htut, K., Pueboobpaphan, R., Mon, E., \& Ratanavaraha, V. (2016). Application of GIS Traffic Accident Analysis: Case Study of the Naypyitaw-Mandalay Expressway (Myanmar). International Journal of Earth Sciences and Engineering, 4(6), 342-345.

Iligan, A. (2017). PNP: Bad turning is leading cause of vebicular accidents in 2016. Retrieved from http://www.topgear.com.ph/news/motoring-news/bad-turning-accident-PH-a00188-20170517.

Ahmed, I., Ahmed, B., \& Hainin, M. (2014). Road Traffic Accident Characteristics in Dhaka, Bangladesh. Jurnal Teknologi, 71(3), 75-82.

JP Research India PVT LTD. (2016). Ahmedabad Urban Road Accident Study. Retrieved from http://rassi.org.in/pdf/Ahmedabad $\% 20$ Urban $\% 20$ Accident $\% 20$ Study $\% 202016$.

Kumar, S., and Toshniwal, D. (2016). A data mining approach to characterize road accident locations. Journal of Modern Transport, 24(1), 62-72.

Moons, E., and Brijs, T. (2009). Spatial Modelling of risk in traffic safety on the road network. Association for European Transport and Contributors, 1-16. Retrieved from https://www.researchgate.net/publication/268198544_Spatial_modelling_of_risk_in_traffic_safety_ on_the_road_network.

Palangchao, H. (2014). Vehicular Accidents Claim 120 lives in CAR for 2014. Baguio Midland Courier. Retrieved from http://baguiomidlandcourier.com.ph/front.asp?mode=archives/2015/january/1-42015/front5.txt.

Punay, E. (2017). 34 Pinoys die daily in road mishap. The Philippine Star Global. Retrieved from https://www.philstar.com/headlines/2017/05/21/1702367/34-pinoys-die-daily-road-mishaps.

Ramos, M. (2014). GIS in PNP (A Logical Intervention Plan). Retrieved from http://mischelleramosjunio.blogspot.com/2014/08/logical-pnp-intervention-plan.html.

Royal Society for the Prevention of Accidents. (2017). Driver Fatigue and Road Accidents Factsheet. Retrieved from www.rospa.com.

Shafabakhsh, G., Famili, A. \& Bahadori, M. (2017). GIS-based spatial analysis of urban traffic accidents" Case study in Mashhad, Iran. Journal of Traffic and Transportation Engineering, 4(3), 290-299.

Sharma, S. M. (2016). Road Traffic Accidents in India. International Journal of Advanced and Integrated Medical Sciences, 1(2), 57-64. 
Sy, K. (2017). Road Crash Numbers: Looking at the Data Source. Retrieved from https://www.rappler.com/move$\mathrm{ph} /$ issues/road-safety/166151-road-crashes-philippines-awareness-safety.

World Health organization. (2018). World Traffic Injuries. Retrieved from www.who.int/mediacentre/factsheets/fs358/en/. 